\title{
Transient Stability Analysis of Hu-Liao HVDC and AC Parallel Transmission System*
}

\author{
Peng Ye ${ }^{1}$, Yuqiu Sui ${ }^{1}$, Yinghua Yuan ${ }^{1}$, Xiaoming Li $^{1}$, Jiaqi Tao ${ }^{2}$ \\ ${ }^{1}$ Northeast Electric Power Research Institute Co. Ltd Shenyang, China; ${ }^{2}$ Northeast China Grid Company Limited Shenyang, China. \\ Email: yepeng_126@sina.com \\ Received June $17^{\text {th }} 2010$; revised July $10^{\text {th }} 2010$; accepted July $17^{\text {th }} 2010$.
}

\begin{abstract}
In this paper, transient stability analysis was focused on Hu-Liao HVDC and AC parallel transmission system. The Hu-Liao HVDC project was introduced; Simulation method and mathematic models of AC and DC systems were studied as well as corresponding regulators and controllers. The dynamic performance and the interaction between AC and $D C$ systems during serious disturbance were researched by detail time-domain simulation. Comparison was also made under different operation schemes. The research will bring important and significant reference for further operation and stability control of Hu-Liao HVDC and AC system.
\end{abstract}

Keywords: HVDC, Transient Stability, Control Strategy, Time-Domain Simulation

\section{Introduction}

Since the first High Voltage Direct Current transmission project was commissioned into commercial operation in 1954, HVDC has been developed so rapidly that it has been widely applied in such fields as large power transmission over long distance, interconnecting two asynchronous systems, power transmission through submarine cables for supplying power to islands and so on. Compared with three-phase AC transmission systems, conventional HVDC is superior in the following aspects [1]: Firstly, HVDC need less cost in constructing and operating; Secondly, it needs not keep operating synchronously between the two AC systems; Thirdly, it is easy to control and adjust power flow, etc.

Among the many HVDC long transmission schemes around the world, very few operate in parallel to $\mathrm{AC}$ transmission of comparable capacity. Problems for parallel $\mathrm{AC} / \mathrm{DC}$ operation is primarily related with the coordination between AC and DC power flows and how each system reacts to any disturbance [2]. It is well known that AC transmission systems have the inherent means to reschedule their power flows and to provide timely and sufficient synchronizing torque to secure such flows following disturbances such as AC faults, load rejection or generator tripping, etc. How a HVDC in parallel to AC system reacts in those situations has always been a cen-

*This paper is supported by key project of State Grid Cooperation of China: "Dynamic behavior and coordination control of AC and DC transmission system in northeast electric network" tral question, particularly for planning and daily operation of such a complex scheme. In reference [3-6], the interaction action between AC and DC parallel transmission system were studied, the theory and operation rules of such power system were demonstrated with simulation examples. Results show that HVDC schemes in parallel operation with AC transmission are prone to both transient swing angle and voltage instabilities. And the risks of instability will increase during disturbances. In reference [7-9], research on advance control strategy for a HVDC scheme in parallel operation with AC systems was discussed. By these unconventional control strategies, the HVDC scheme can actively participate in the instantaneous rescheduling of power and improve the dynamic performance of power network. In reference [10,11], a real AC and DC parallel transmission system in South China was studied from operation and control aspects.

The HuLunbeier-Liaoning (abbreviated as Hu-Liao hereinafter) HVDC project was the first AC/DC parallel transmission system in North China, which was employed to transfer electricity from Hulunbeier energy center to Liaoning province. In particular, in the sending side of HVDC, Hulunbeier has a very weak network. As a result, the stability problem in operation is very critical. It is a challenge work for the operator to keep such a special AC/DC parallel transmission system operating in an economic and secure state.

In this paper, transient stability analysis was focused 
on the Hu-Liao HVDC and AC parallel transmission system. The Hu-Liao HVDC project was introduced; Simulation method and mathematic models of $\mathrm{AC}$ and DC systems were studied as well as corresponding regulators and controllers. The dynamic performance and the interaction between AC and DC systems during serious disturbance were researched by detail simulation. Comparison was also made under different operation schemes. The research will bring important and significant reference for further operation and stability control of $\mathrm{Hu}-$ Liao HVDC and AC system.

\section{Hu-Liao HVDC and AC Parallel Transmission System}

Northeast China Electric Power Network System consists of four provincial networks, Liaoning, Jilin, Heilongjiang and East of Inner Mongolia. These networks have been linked with $500 \mathrm{kV}$ transmission lines. And Liaoning electric network is connected with Huabei network by back-to-back HVDC links with a rated capacity of 1500 MW. Figure 1 shows the schematic of Hu-Liao HVDC and $\mathrm{AC}$ parallel transmission system.

Hulunbeier is rich in coal, large scale power plants are under constructing. Liaoning province is a rapid developing province in economic but much lack of energy. So based on the mutual interest and the idea of optimizing resources, Hu-Liao HVDC project is put into operation.

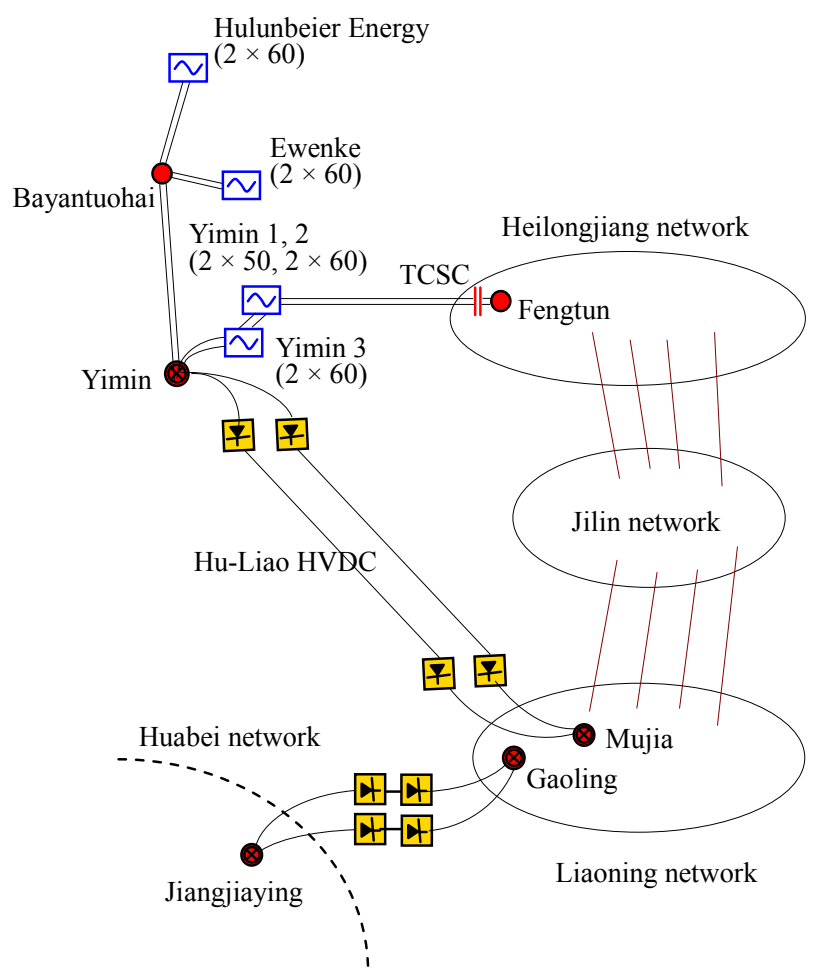

Figure 1. Schematic of Hu-Liao HVDC and AC parallel transmission system
Hu-Liao HVDC transmission is a bipolar 12-pulse HVDC transmission system with rated DC voltage \pm 500 $\mathrm{kV}$, rated power $3000 \mathrm{MW}$, rated current $2500 \mathrm{~A}$. Overhead lines have a length of $908 \mathrm{~km}$ long. Yimin converter station locates at east of Inner Mongolia, which is $10 \mathrm{~km}$ away from Yimin power plants. It acts normally as a rectifier and its AC side rated voltage is $500 \mathrm{kV}$. Mujia converter station is in the center of Liaoning province and connected with Anshan $500 \mathrm{kV}$ station with two $21 \mathrm{~km}$ lines. It acts principally as an inverter and its $\mathrm{AC}$ side rated voltage is also $500 \mathrm{kV}$. The Hu-Liao HVDC transmission system operation modes include bipolar mode, monopolar ground return mode, monopolar metallic return model and monopolar parallel line ground return model. The HVDC system can be operated under rated voltage and lower voltage. The $\mathrm{Hu}-\mathrm{Liao} \mathrm{HVDC}$ transmission normally operates in $\mathrm{P}$ mode (constant power control mode). I mode (constant current control mode) can be used as a back-up mode.

As mentioned above, large scale power plants are under construction in Hulunbeier. Before Hu-Liao HVDC implemented, there are two power plants, namely: Yimin 1 and 2, with altogether capacity of $2200 \mathrm{MW}$. Electric power is transferred to the west of Heilongjiang province through two $500 \mathrm{kV}$ lines. At Fengtun station, Thyristor Controlled Series Compensation (TCSC) is installed to improve the transfer capability. Up to now, three new power plants, Yimin 3, Hulunber Energy and Ewenke, are set up. The electric power capacity is $3600 \mathrm{MW}$ and they are mainly transferred to Liaoning province by Hu-Liao HVDC system.

There are disconnecting switches between the buses of Yimin 1, 2 and Yimin 3 power plants. When they are closed, Hu-Liao HVDC and AC system are operating in parallel. There is power exchanging through AC and DC system. Generally, when AC and DC system is operated in parallel, the fault occurred in either AC or DC system would lead to instantaneous or permanent power imbalance in power system, and quantity of power will shift through AC and DC system, which would be a great impact to transient stability. It is a challenge for system operation, especially due to such a weak delivering side.

\section{Mathematic Models and Criterian in Simulation}

The electromechanical transient simulation of this AC and DC hybrid system was made through PSASP. Northeast electric power network data include about 1500 buses, 330 generators and two groups of DC lines. Only $500 \mathrm{kV}$ and $220 \mathrm{kV}$ voltage network are considered in calculation. As PSASP offered adequate mathematics models for each type of electric elements, a majority of them are defined by PSASP according to the requirement of the simulation. Individuals are developed through user program interface such as DC and TCSC models and 
controllers. The details are as follows:

\subsection{Models for AC System}

For most of generators, five-order model is adopted, in which the variations of $\mathrm{E}_{\mathrm{q}}{ }^{\prime \prime}, \mathrm{E}_{\mathrm{d}}{ }^{\prime \prime}$ and $\mathrm{E}_{\mathrm{q}}{ }^{\prime}$ are considered. They are fit for detail simulation of salient pole synchronous generators. As for the individual small hydroelectric equipment, two-order model is adopted, in which it is approximately hold that $\mathrm{E}_{\mathrm{q}}^{\prime}$ could keep constant. Most of wind turbines are modeled as doubly-fed direct-drive wind power generators. The models of the corresponding regulators such as excitation system, speed control system and PSS, are selected and defined in the software according to the practical case.

For system load, it is described as combination of fifty percent constant impedance and fifty percent induction motor during dynamic simulation. Three-order model of induction motor is used here to simulate the dynamic features of loads. The parameter of stator leakage reactance is selected as $0.18 \mathrm{pu}$.

The electric distance is relatively near between TCSC and DC lines. The Yi-Feng TCSC is composed of two parts: fixed part and variable part. The fixed part occupies thirty percent of the total transmission line capacity and the variable part occupies fifteen percent. In the dynamic process, the TCSC acts as follows: The fixed part is sure not to be bypassed when fault occurred in transmission lines; The variable part is to be bypassed when three or two phase fault occurred in the line; while when single phase fault occurred, the fault phase is bypassed and the forced compensation will take action in normal phase; The forced compensation will also take action when fault occurred in neighbor line. The bypass time of TCSC is $0.05 \mathrm{~s}$ after fault occurring. The control logic of the variable part is shown in Figure 2. Where, $\mathrm{P}$ and $\mathrm{V}$ are measured power and voltage, which is used for oscillation control; $t_{\text {trigger }}$ is the signal of beginning time and $\mathrm{T}_{\text {forced }}$ is the continuous time of the action. The maximum compensation capacity is forty-five percent.

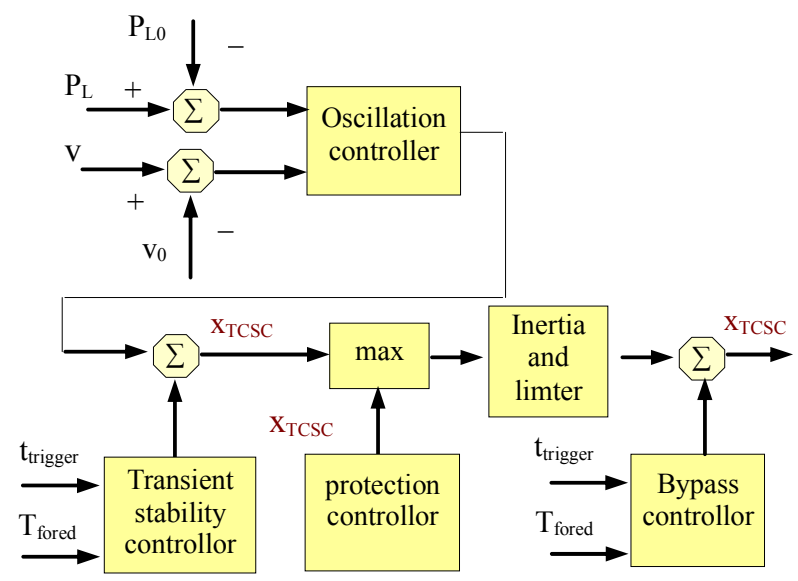

Figure 2. Control scheme of TCSC

\subsection{Models for DC System}

The DC model used in steady state calculation is shown as the following equation, in which approximation was made in reactive power calculation and in this way the equation form was much simplified.

$$
\left\{\begin{array}{l}
P_{a c}=U_{d} I_{d} \\
Q_{a c}=P_{a c} \tan \varphi \\
\cos \varphi \approx U_{d} / U_{d 0}
\end{array}\right.
$$

where, $U_{\mathrm{d} 0}$ is the converter transformer no-load DC voltage, $P_{a c}$ and $Q_{a c}$ is the active and reactive power from AC to DC. $I_{d}$ and $U_{d}$ is the current and voltage of DC line.

In normal operation, HVDC links required to transmit a scheduled power. In such an application, the master control layer receives the power schedule, modifies by auxiliary power control and then converts the power signal into the coordinated bi-pole current order commensurate with the DC voltage. Pole control is the core of HVDC control and activates the appropriate controller of the rectifier and inverter station according to the state of $\mathrm{AC} / \mathrm{DC}$ systems. Then it produces the firing angle for both rectifier and inverter stations. The control scheme is shown in Figure 3.

Pole control at the rectifier side has a current controller, which takes the maximum and minimum current constrains and the VDCOL into consideration. The minimum firing angle control is embedded implicitly in the

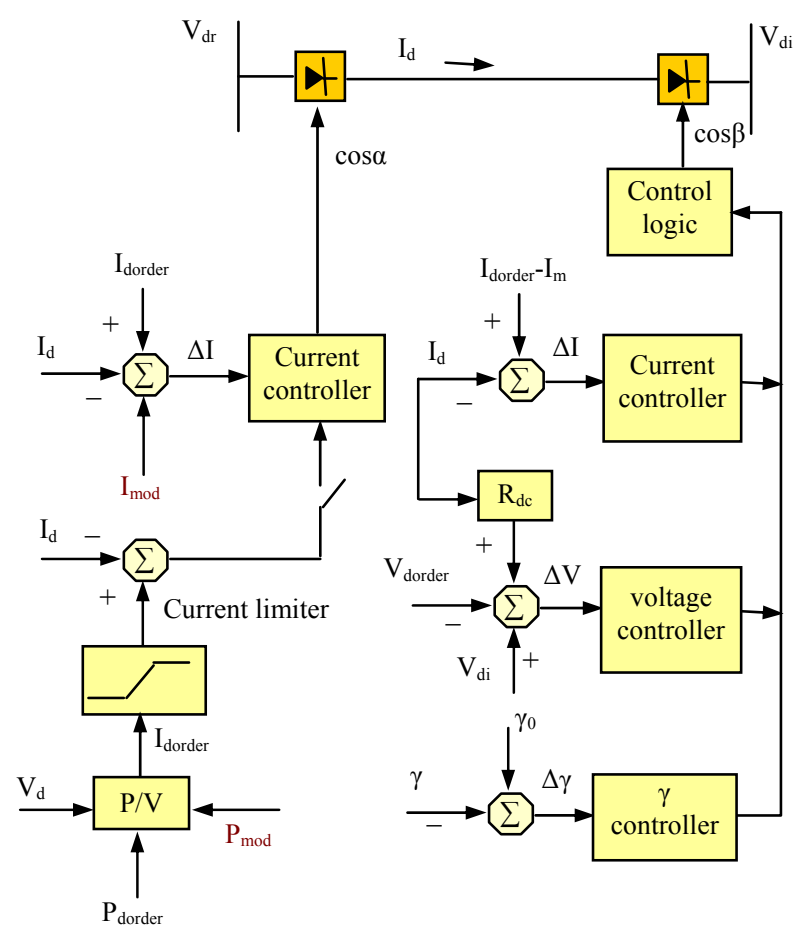

Figure 3. Control scheme of DC system 
current controller by angle limits. Pole control at the inverter station includes a voltage controller, a constant current controller and a constant extinction angle controller. Current error $I_{\mathrm{m}}$ provides a transition between the current control and voltage control to facilitate control stabilization. The shift logic of these controllers is implemented by:

$$
I_{d}=\frac{U_{d 0 r} \cos \alpha-U_{d 0 i} \cos \gamma}{d_{x r}+R_{d}-d_{x i}}
$$

where: $d_{\mathrm{xr}}, d_{\mathrm{xi}}$ are the equivalent resistance of the rectifier and inverter. $R_{\mathrm{d}}$ is the resistance of DC line. $\alpha$ and $\gamma$ correspond to the rectifier ignition angle and inverter extinction angle.

When situation needed, additional control will be joined through $P_{\text {mod }}$ or $I_{\text {mod }}$ to fully exert the DC features of fast power control and improve the dynamic performance of AC system.

\subsection{Criterian for Transient Stability}

According to power system stability guideline of China, to keep transient stability, the following conditions must be satisfied at the same time:

Angle stability: after disturbance, any rotor angle between two generators in the same AC system takes on a damping oscillation.

Voltage stability: the continuous time of low voltage under $0.75 \mathrm{pu}$ is within $1 \mathrm{~s}$. The voltage of pivot buses is above $0.8 \mathrm{pu}$ when the fault is clear.

Frequency stability: the frequency collapse will not happen with secure measures such as loads shedding and generator tripping. The frequency can restore to the normal level and the large unit operation will not be affected.

\section{Transient Stability Analysis}

Transient stability criterion for the studied system requires the system to be stable after clearing of any single fault or successful reclosing. Amount of simulations were done on this system. For AC system, the worst condition occurs when three phase permanent fault happens near Yimin power plants. For DC system, the worst condition occurs when bipolar blocking happens. Stability measures are necessary for most cases.

\subsection{Dynamic Behavior when AC Faults}

The typical case was studied when a permanent three phase fault occurred in the exit of $500 \mathrm{kV}$ Yi-Feng line. The steady state condition is 6 units for DC power sending and DC capacity $3000 \mathrm{MW}$. Stability measure is that three unit tripping in Yimin plants and AC/DC separated within $150 \mathrm{~m}$. Because the close electric distance with Yimin bus, AC bus voltage of Yimin converter reduced a lot and is close to zero in the fault instant. As a result, $\mathrm{DC}$ voltage brought down along with $\mathrm{AC}$ voltage till it can not work its way and quitted temporarily. The misbalance between energy and power of AC system in Yimin and Hulunbeier areas was further increased and the instability of the system became even worse. After one second the fault line is cleared, the AC voltage is recovered. When condition is permitted, DC system restarted and DC power is restored, which is much helpful for AC system stability. Voltage, rotor angle and DC power curves during the disturbance were shown in Figure 4, Figure 5 and Figure 6.

To study the influence of DC power to AC stability, simulation was done under 4 units and different DC power. Results were shown in Figure 7 without measure and in Table 1 with necessary measure. Results showed that power exchanging from AC to DC system is advantageous to improve AC system stability.

\subsection{Dynamic Behavior when DC Faults}

When fault occurred in DC line, the bipolar blocking is the most serious one. In this case, mass power shifts to Yi-feng lines and make a great impact on AC system. If

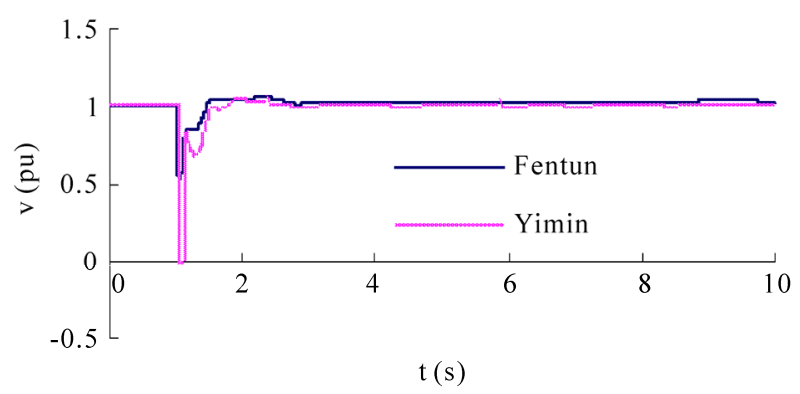

Figure 4. Voltage variation of Yimin and Fengtun bus

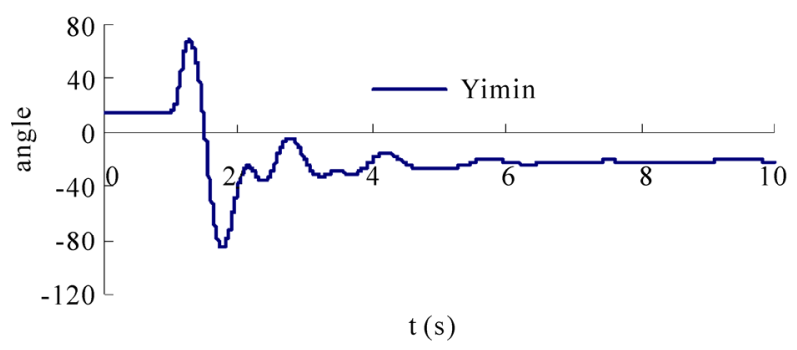

Figure 5. Rotor angle variation of Yimin unit

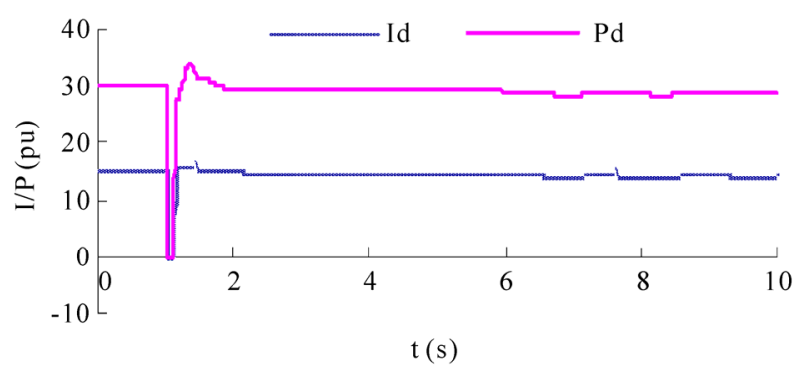

Figure 6. DC power and current variation 


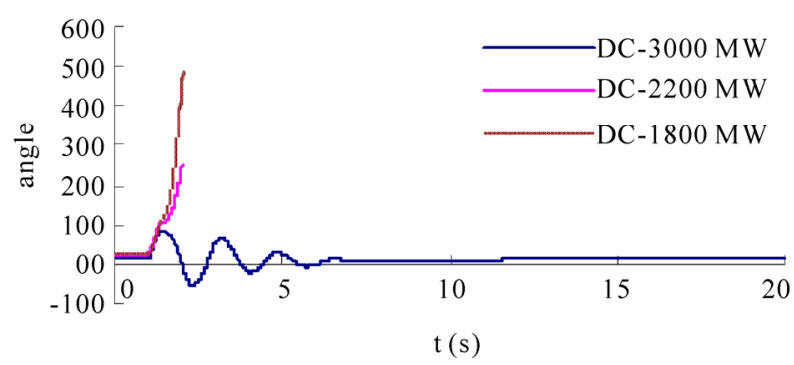

Figure 7. Rotor angle variation of Yimin unit under different DC power

Table 1. Stability measures under different DC power

\begin{tabular}{cl}
\hline DC capacity & \multicolumn{1}{c}{ Measures To Keep stability } \\
\hline $3000 \mathrm{MW}$ & No measures needed \\
$2600 \mathrm{MW}$ & two units tripping in Yimin plants within $150 \mathrm{~ms}$ \\
$2200 \mathrm{MW}$ & $\begin{array}{l}\text { two units tripping in Yimin plants and AC/DC } \\
\text { separated within } 150 \mathrm{~ms}\end{array}$ \\
$1800 \mathrm{MW}$ & and AC/DC separated within $150 \mathrm{~ms}$
\end{tabular}

DC can restart successfully, the oscillation can be appeased and AC system keeps stable; Else, AC system will lose stability without secure control measures.

In the above simulation, The DC system experiences a restart failure for the first time and a success start over a lowering voltage for the second time. Along with DC restore, the AC system got a smooth resumption. To keep stability, the control measures under different DC powers are listed in the following table in case of bipolar blocking and failure restart. Results showed that the severity of the fault is closely related with the exchanging power between AC and DC system and the unit boot mode of Yimin plants.

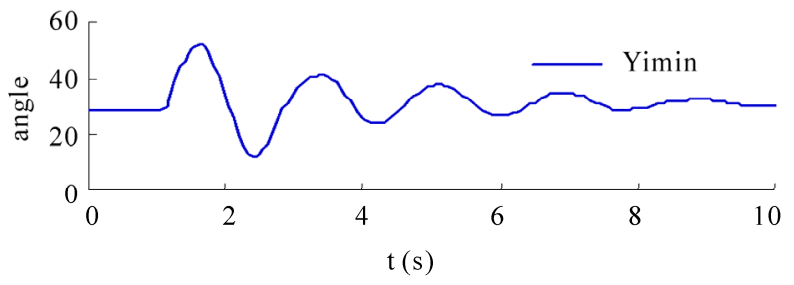

Figure 8. Rotor angle variation of Yimin unit

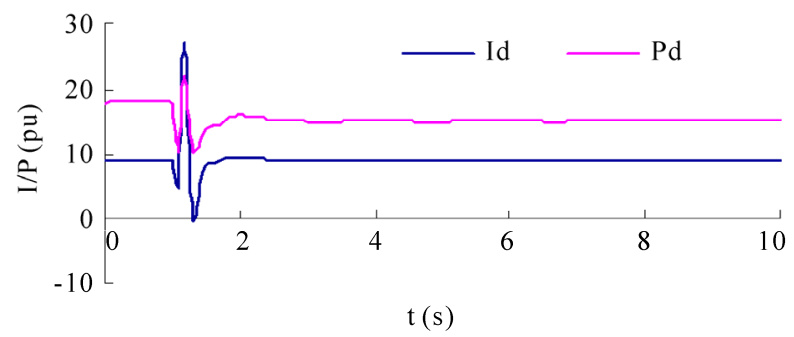

Figure 9. DC power and current variation
Table 2. Stability measures under different DC power in bipolar blocking

\begin{tabular}{cc}
\hline DC capacity & Measures to keep stability \\
\hline 6 unit, $3000 \mathrm{MW}$ & 5 units tripping \\
4 unit, $3000 \mathrm{MW}$ & 3 units tripping \\
4 unit, $2200 \mathrm{MW}$ & 2 units tripping \\
4 unit, $1800 \mathrm{MW}$ & 2 units tripping \\
\hline
\end{tabular}

\subsection{Additional Controls for AC/DC Hybrid System}

The following simulation was done in such an operation: 4 units for DC power sending and DC power $1800 \mathrm{MW}$. First, to research the features of additional controls for AC/DC hybrid system, simulations were calculated by three cases: that is no additional control, with TCSC forced compensation control and with DC emergency power control. Results were shown in Figure 10. When the additional control of TCSC and DC is activated, the transient stability can be improved but in a limit compared with unit tripping under such serious faults.

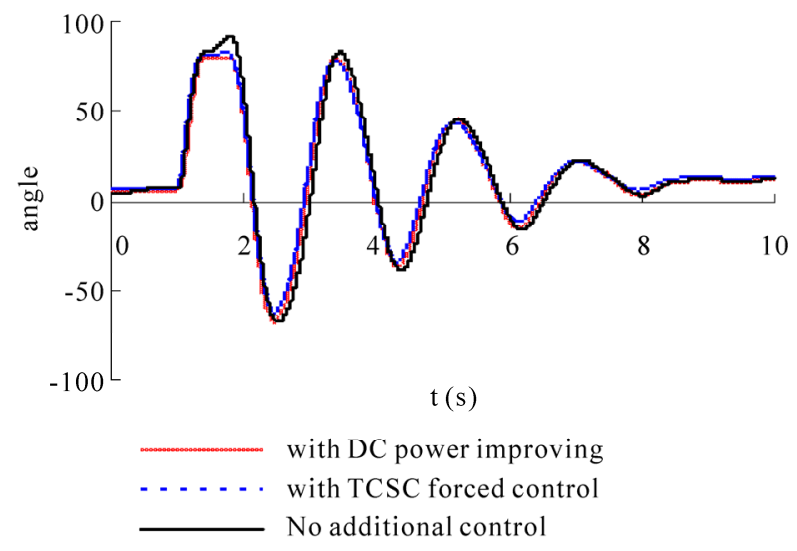

Figure 10. Additional control effect for AC and DC hybrid system

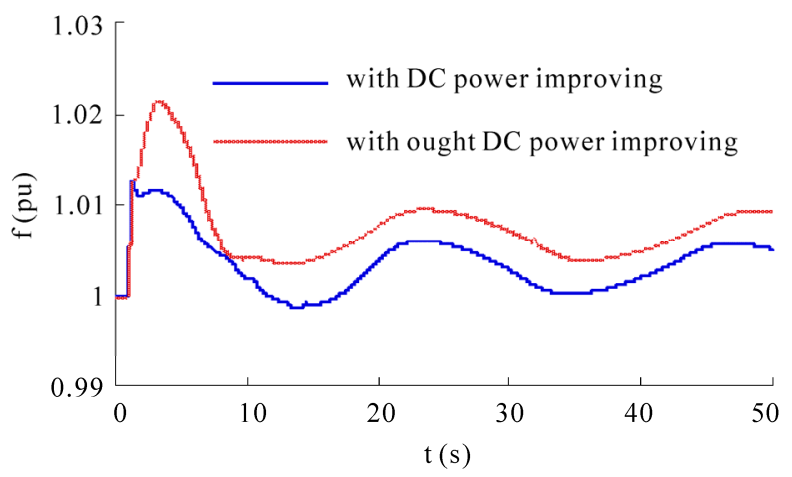

Figure 11. Ewenke frequency when $\mathrm{AC}$ and $\mathrm{DC}$ is separated 
Secondly, frequency restore will meet problem when $\mathrm{AC} / \mathrm{DC}$ is separated during dynamic process. It is mainly due to the AC simple structure in the rectifier side of DC system and the mismatch power between the DC system and $\mathrm{AC}$ islands system. The frequency simulation was done in two cases: without additional DC control and improving DC power by $15 \%$. Results show that frequency can be recovered in an acceptable range with DC control.

The HVDC system with island generators in sending side will meet a frequency stability problem when the $\mathrm{AC} / \mathrm{DC}$ parallel transmission system changed from connection into separation. Frequency stability depends on the generation capacity in the sending side and the HVDC power. Improving the generation capacity in the sending side and decreasing the mismatch power between the generation capacity and DC power in the sending side will be helpful to the improvement of frequency stability. DC emergency power control is necessary in the frequency control process. Amount of simulation has done to explore the frequency stability rules of such a special HVDC system. The results and stability terms are listed in the following table, which shows the relationship between the mismatch power and frequency stability. Advanced DC additional power controller is still needed for delicate frequency control.

\section{Conclusions}

In this paper, transient stability analysis was carried out focus on the Hu-Liao HVDC and AC parallel transmission system. The dynamic performance and the interaction between $\mathrm{AC}$ and $\mathrm{DC}$ systems during serious disturbance were researched by detail simulation. Only several examples are showed and discussed here as space limited. Results showed that:

1) As for the weak network of Hu-Liao rectifier side and the limit of AC transfer capacity, transient stability problem is rather serious. The dynamic interaction between $\mathrm{AC}$ and $\mathrm{DC}$ system during disturbance is intense.

2) The exchanging power between $A C$ and DC system have a corresponding influence on dynamic performance and control strategies for keeping transient stability. Power exchanging from AC to DC system is advantageous to improve AC system stability.

3) By proper control, TCSC forced compensation and DC emergent power transfer can improve system stability. Compared with generator tripping and AC/DC separating, they are only a subsidiary control method for the researched system.

4) Frequency stability by additional DC controls is necessary when AC/DC parallel transmission system changed from connection into separation.

The research will bring important and significant reference for further operation and stability control of Hu-Liao HVDC and AC system. Further research still
Table 3. The maximum line transmission of Yimin-Yimin converter to keep frequency stability

\begin{tabular}{ccc}
\hline \multicolumn{2}{c}{ DC island generation } & $\begin{array}{c}\text { Line transmission limit of } \\
\text { Yimin-Yimin converter (MW) }\end{array}$ \\
\hline Unit number & Unit generation & $-650 \sim 850$ \\
3 & No limit & $-350 \sim 850$ \\
3 & $>1550$ & $-350 \sim 550$ \\
2 & $<1550$ & $-350 \sim 550$ \\
& $>650$ & $-50 \sim 550$ \\
\hline
\end{tabular}

remained on the topics such as the optimal operation of AC and DC system, DC separated operation and control, strategies design for stability control and so on.

\section{REFERENCES}

[1] IEEE Committee Report, "AC-DC Economics and Altematives-1987 Panel Session Report," IEEE Transaction on Power Delivery, Vol. 5, No. 4, October 1990, pp. 1956-1976.

[2] H. Ritva, "Torsional Interaction between an HVDC Link and Large Turbine-Generators," Saehkoe Electricity and Electronics, Vol. 62, No. 6, June 1989, pp. 38-41.

[3] IEEE Committee Report, "HVDC Controls for System Dynamic Performance," IEEE Transaction on Power system, Vol. 6, No. 2, May 1991, pp. 743-752.

[4] R. John and U. Edvina "Study of Power Transfer Capability of DC Systems Incorporating AC Loads and a Parallel AC Line," IEEE Transactions on Power Delivery, Vol. 12, No. 1, January 1997, pp. 426-434.

[5] K. W. V To, A. K. David and A. E. Hammad, "A Robust Coordinated Control Scheme for HVDC Transmission with Parallel AC System," IEEE Transactions on Power Delivery, Vol. 5, No. 4, July 1994, pp. 1710-1716.

[6] A. E. Hammad, "Stability and Control Strategy for Parallel Operation of AC and DC Transmission Systems," Proceedings of 6th International Conference on AC and DC Power Transmission, London, September 1996, pp. 163-171.

[7] A. E. Hammad, "Stability and Control of HVDC and AC Transmission in Parallel," IEEE Transactions on Power Delivery, Vol. 14, No. 4, October 1999, pp. 1545-1551.

[8] H. Z. Cai, Z. H. Qu and D. Q. Gan, "A Nonlinear Robust HVDC Control for a Parallel AC/DC Power System," Computers and Electrical Engineering, Vol. 29, No. 1, 2002, pp. 135-150.

[9] B. L. Quan, "Stability of Tian-Guang HVDC and HVAC Transmission System," ICPST, Beijing, 1994.

[10] Y. Jing, Z. Ren, B. Q. Li and S. R. Ma, "Research on Transmission Capability of Tian-Guang AC and DC Hybrid System," Power System Technology, Vol. 26, No. 8, 
2002, pp. 52-55.

[11] Y. Jing, L. C. Li, Z. Ren, "Stability Control of Tian-guang AC and DC Parallel Transmission System,"
Automation of Electric Power Systems, Vol. 26, No. 1, 2002, pp. 49-52. 